\title{
The Relationship between Mastery Experience and Teacher Self-Efficacy: A Meta-Analytic Review
}

\author{
Mohamad Sahari Nordin \\ Kulliyyah of Education, \\ International Islamic University Malaysia \\ Kuala Lumpur, Malaysia \\ Mohd Burhan Ibrahim \\ Kulliyyah of Education, \\ International Islamic University Malaysia \\ Kuala Lumpur, Malaysia
}

\author{
Lilia Halim \\ Faculty of Education, \\ National University of Malaysia, \\ Bangi, Malaysia \\ Enas Said Abu Libdeh \\ College of Education, \\ Al Ain University of Science and Technology, \\ Abu Dhabi, United Arab Emirates
}

\begin{abstract}
Despite the potency of teacher self-efficacy, not much is known about what makes a teacher efficacious. Hence, this meta-analysis took to the task of examining the likelihood and magnitude of the relationship between mastery experience and teacher self-efficacy, and identify moderators of the association. A total of 39 original studies involving 9,560 teachers were examined. The respondents were teachers of various school levels, and 15 of the studies involved both primary and secondary school teachers. Almost two thirds of the primary studies were conducted in Western settings, while the rest were Asian studies. To identify the moderators, the study applied a meta-regression procedure. The results supported the expectation that mastery experience positively influences teacher self-efficacy. Additionally, it was discovered that differences in research design, school level, and culture impacted the variability of the relationship. Studies that employed experimental designs produced marked effects on the relationship. An interesting finding was that culture moderated the relationship between mastery experience and teacher self-efficacy where Western teachers were found to exhibited superior teacher self-efficacy than their Asian counterparts.
\end{abstract}

Keywords: Meta-Analysis; Teacher Self-Efficacy; Mastery Experience; In-service Training; Cultural Differences

\section{INTRODUCTION}

According to Bandura (1977), self-efficacy is the nucleus of human agency. An individual's efficacy beliefs determine the effort he/she puts in and the levels of his/her perseverance in the face of difficulties and adversities. Self-efficacy beliefs prompt a person's aspirations, goals, and motivation. Accordingly, teacher self-efficacy refers to a teacher's judgment and expectations of being in control of the teaching and learning environment, and being able to execute instructions satisfactorily (Pajares, 1992). It is a psychological construct that affects a teacher's decision on whether to attempt an instructional task, invest a certain amount of effort, and be persistent in expanding time and energy (Bandura, 1977). An efficacious teacher would more likely attribute student success and failure to the instructional efforts within his or her control, and this has been consistently found to be the factor that makes a difference in student learning. 
Despite the potency of teacher self-efficacy, not much is known about what makes a teacher efficacious (Klassen \& Tze, 2014; Kleinsasser, 2014). Empirical data on the sources of teacher self-efficacy, including intervention studies, are growing. However, the findings documented are far from conclusive. While quite a number of studies found significant impacts in favour of teacher self-efficacy interventions (e.g., Cadungog, 2015; Cantrell \& Hughes, 2008), others recorded a failure to enhance teachers' predisposition (Yenice, 2009). Still, there are studies that reported negative relationships (Woolfson \& Brady, 2009; Yeo, 2008). Therefore, it is imperative to meta-analyse the extant literature in order to address this uncertainty.

The aim of this meta-analytic review was to summarize the data on the relationship between mastery experience and teacher self-efficacy, and to verify the variables that act as moderators of the association. The results of the exercise would substantiate the direction and magnitude of the effects of mastery experience on teacher-efficacy. More precisely, the questions driving the present review were:

1. What is the nature of the relationship between mastery experience and teacher selfefficacy?

2. To what extent do research design, outcome measure, school level, and culture moderate the relationship between mastery experience and teacher self-efficacy?

\section{Mastery Experience and Teacher Self-Efficacy}

Bandura $(1977,1997)$ proposed four sources of efficacy beliefs, namely vicarious experience, verbal persuasion, psychological responses, and mastery experience. Mastery experience, in particular, would directly inform the teacher of his or her capabilities. The experience prompts the teacher to reflect on and judge his or her ability to be in control of teaching tasks. Bandura (1977) pointed out that, "successes raise mastery expectations; repeated failures lower them, particularly if the mishap occurs early in the course of events" (p. 195). Thus fruitful pedagogical experience (Ghanizadeh \& Moafian, 2011; Ransford et al., 2009), satisfaction with one's own professional performance (Tschannen-Moran \& Hoy, 2002), and satisfaction with teacher-student interactions (Yenice, 2009) are expected to expand teacher efficacy beliefs. Teachers' in-service training allows for professional development in which the teacher sequentially gains confidence, enhances instructional skills, constructs meaningful knowledge, and takes on new responsibilities.

\section{METHODS}

\section{Criteria for Inclusion of Studies}

This review defines teacher self-efficacy as a teacher's conviction or beliefs about his or her own capabilities to organize and accomplish instructional tasks (Bandura, 1997). The definition covers operationalized constructs that measure personal teaching efficacy (Gibson \& Dembo, 1984), teaching efficacy belief (van Acker, 2013), and self-efficacy in specific teaching tasks, including student engagement, classroom management, instructional strategies (Tschannen-Moran \& Hoy, 2001), science teaching efficacy beliefs (Riggs \& Enochs, 1990), and inclusive instructions (Sharma, Loreman, \& Forlin, 2012). Mastery experience, on the other hand, refers to teachers' personalized professional success or failure experiences. Eligible 
studies included those that tested the associations between teacher self-efficacy and in-service training, pedagogical experience (Ghanizadeh \& Moafian, 2011; Ransford et al., 2009), and

Additionally, the review refers to Lipsey and Wilson's (2001) seven inclusion criteria to determine studies that would be included and excluded in the meta-analysis. First, the sample should comprise practising teachers of elementary and secondary schools. Second, each study should disclose the relationship between mastery experience and teacher self-efficacy. Third, the studies must identify at least one measure of mastery experience. Fourth, the studies should contain adequate statistical information to enable the computation of effect sizes (ES). Fifth, the studies are reported in English. Sixth, they should be conducted after 1977, the year Bandura proposed the idea of self-efficacy. Finally to avoid publication bias, referred to as the file-drawer effect which results from the practice of researchers filing away studies with negative outcomes and publishing only statistically significant effects, the meta-analysis included both published and unpublished data.

The studies targeted for the meta-analysis were identified through computer searches of databases like the Education Resource Information Center (ERIC), ProQuest Education Journals, ProQuest Dissertations and Theses Global, and SCOPUS, using the following search terms and their variations: teacher self-efficacy, personal teaching efficacy, teaching efficacy, mastery experience, in-service training, and teacher professional development. To enable comparisons across studies, a common matrix was used, i.e. Pearson's correlation, with Fisher $\mathrm{z}$ transformation procedure using Comprehensive Meta-Analysis version 3 (CMA) software. To test the adequacy of moderation models, we applied the random-effect model of metaregression procedure (Borenstein, Hedges, Higgins, \& Rothstein, 2009).

\section{RESULTS}

\section{Overall Relationship between Mastery Experience and Teacher Self-Efficacy}

Table 1 summarizes the salient features of the studies included in the meta-analytic review. A total of 31 research reports containing 39 original studies involving 9,560 teachers were documented between 1994 and 2016. The sample size of the studies ranged from 11 to 1,484 teachers with an average of 242 per study. The respondents were teachers of various school levels; 18 studies examined primary school teachers, while six examined teacher efficacy among secondary school teachers. Each of the 15 other studies involved both primary and secondary school teachers. In addition, $74 \%$ of the studies were conducted in Western settings, while the rest were Asian studies.

The studies employed varied research designs. A majority were categorized as crosssectional surveys $(49 \%)$, followed by pre-post single group studies $(35 \%)$. The remaining seven were experimental studies. The instrument most widely used was Tschannen-Moran and Hoy's Teacher Efficacy in Instruction scale (SEI), followed by Gibson and Dembo's Teacher Personal Self-Efficacy Scale (PTE), Riggs and Enoch's Teaching Mathematics/Science Efficacy questionnaire (PTSE) and its variants, and locally- and researcher-developed measures of efficacy beliefs. Of the 39 studies, one-third documented an insignificant relationship between mastery experience and teacher self-efficacy. 
Table 1

Studies Included in the Teacher Self-Efficacy Meta-Analysis

\begin{tabular}{|c|c|c|c|c|c|c|}
\hline Study & $\mathrm{n}$ & Year & Design & Level & Culture & Results \\
\hline Chao et al. (2016) & 408 & 2016 & Pre-Post & $\mathrm{P} \& \mathrm{~S}$ & Asian & Sig. \\
\hline Azar (2010) & 125 & 2010 & Experiment & $\mathrm{P} \& \mathrm{~S}$ & Asian & NS \\
\hline Karimi (2011) & 60 & 2011 & Experiment & $P \& S$ & Asian & Sig. \\
\hline Ghanizadeh \& Moafian (2011) & 779 & 2011 & Survey & $P \& S$ & Asian & Sig. \\
\hline Yenice (2009) & 139 & 2009 & Survey & Primary & Asian & NS \\
\hline Cadungog (2015) & 400 & 2015 & Survey & Secondary & Asian & Sig. \\
\hline Mohamadi (2011) & 284 & 2011 & Survey & Secondary & Asian & Sig. \\
\hline Nordin $(2001)$ & 140 & 2001 & Survey & Secondary & Asian & Sig. \\
\hline Yeo et al. (2008) & 55 & 2008 & Survey & Secondary & Asian & NS \\
\hline Cantrell \& Hughes (2008) & 22 & 2008 & Pre-Post & $\mathrm{P} \& \mathrm{~S}$ & Western & Sig. \\
\hline Henson (2001) & 11 & 2001 & Pre-Post & $P \& S$ & Western & Sig. \\
\hline Zambo \& Zambo (2008); S2 & 31 & 2008 & Pre-Post & $P \& S$ & Western & Sig. \\
\hline Zambo \& Zambo (2008);S1 & 32 & 2008 & Pre-Post & $\mathrm{P} \& \mathrm{~S}$ & Western & Sig. \\
\hline Bruce \& Flynn (2013); S1 & 77 & 2013 & Pre-Post & Primary & Western & Sig. \\
\hline Bruce \& Flynn (2013); S2 & 38 & 2013 & Pre-Post & Primary & Western & NS \\
\hline Bruce \& Flynn (2013); S3 & 52 & 2013 & Pre-Post & Primary & Western & Sig. \\
\hline Bruce \& Flynn (2013); S4 & 11 & 2013 & Pre-Post & Primary & Western & NS \\
\hline Bruce \& Flynn (2013); S5 & 43 & 2013 & Pre-Post & Primary & Western & NS \\
\hline Lumpe et al. (2012) & 450 & 2012 & Pre-Post & Primary & Western & Sig. \\
\hline Haney et al. (2007) & 18 & 2007 & Pre-Post & Secondary & Western & Sig. \\
\hline Ross (1994) & 40 & 1994 & Pre-Post & Secondary & Western & NS \\
\hline Edwards \& Newton (1995); S1 & 26 & 1995 & Experiment & $\mathrm{P} \& \mathrm{~S}$ & Western & NS \\
\hline Edwards \& Newton (1995); S2 & 80 & 1995 & Experiment & $\mathrm{P} \& \mathrm{~S}$ & Western & NS \\
\hline Gaudreau et al. (2013) & 51 & 2013 & Experiment & Primary & Western & Sig. \\
\hline Ross \& Bruce (2007) & 106 & 2007 & Experiment & Primary & Western & NS \\
\hline Trimmell (2015) & 50 & 2015 & Experiment & Primary & Western & Sig. \\
\hline Tschannen-Moran \& Hoy (2002) & 255 & 2002 & Survey & $\mathrm{P} \& \mathrm{~S}$ & Western & Sig. \\
\hline $\begin{array}{l}\text { Tschannen-Moran \& Johnson (2007); } \\
\text { S1 }\end{array}$ & 74 & 2007 & Survey & $P \& S$ & Western & Sig. \\
\hline $\begin{array}{l}\text { Tschannen-Moran \& Johnson (2007); } \\
\text { S2 }\end{array}$ & 181 & 2007 & Survey & $P \& S$ & Western & Sig. \\
\hline Kosko \& Wilkins (2009)S2 & 950 & 2009 & Survey & Primary & Western & Sig. \\
\hline Lee (2013) & 79 & 2013 & Survey & Primary & Western & Sig. \\
\hline Ransford et al. (2009) & 133 & 2009 & Survey & Primary & Western & Sig. \\
\hline Swackhamer et al. (2009) & 88 & 2009 & Survey & Primary & Western & NS \\
\hline Tschannen-Moran \& Johnson (2011) & 648 & 2011 & Survey & Primary & Western & Sig. \\
\hline Tweed (2013) & 124 & 2013 & Survey & Primary & Western & NS \\
\hline Woolfson \& Brady (2009) & 199 & 2009 & Survey & Primary & Western & NS \\
\hline Kosko \& Wilkins (2009)S1 & 950 & 2009 & Survey & Primary & Western & Sig. \\
\hline Malinen et al. (2013) & 867 & 2013 & Survey & $\mathrm{P} \& \mathrm{~S}$ & Western & Sig. \\
\hline Van Acker (2013) & 1484 & 2013 & Survey & $P \& S$ & Western & Sig. \\
\hline
\end{tabular}

Note: Results, 'NS' indicates statistically insignificant relationship; 'Sig.' indicates statistically significant relationship. 
The results of the basic meta-analysis show that the sample-size-weighted mean correlation between mastery experience and teacher self-efficacy was .24, with a 95\% confidence interval (CI) of .165 to .305 , the $\mathrm{z}$-value for the test of null was $6.38, \mathrm{p}=.001$. It is very likely that the ES was not zero. The nontrivial positive overall ES was also supported by the results of pass-fail $\mathrm{N}$ test. The results reveal that 4,614 additional studies with statistically insignificant ESs are called for to negate the positive causal relationship between mastery experience and teacher self-efficacy to the value of .10. In addition, the results of Egger's regression test (Egger, Smith, Schneider, \& Minder, 1997) of the intercept suggested the absence of file-drawer bias; $\mathrm{t}(37)=0.36, \mathrm{p}=.72$. This means that the primary studies included in the meta-analysis were not systematically selected in favour of positive and statistically significant results.

\section{Predictors of Mastery Experience-Teacher Self-Efficacy Relationship}

Another objective of this review was to examine whether the effect size of mastery experienceself-efficacy is related to research design, outcome measure, school level, culture, and the covariate, year of publication. To answer the question, the study tested two prediction models using meta-regression procedure. The first model included five predictors, while the second meta-regression tested the adequacy of a four-predictor model, minus the outcome measure. The criterion variable for both prediction equations was the ES.

The results of a meta-regression of the five-predictor model show that model adequately fitted the data. The simultaneous test of all predictors, without the intercept, was not zero [Q(9) $=17.63, \mathrm{p}=.04]$; thus the null was rejected. It is very likely that that at least one of the predictors was methodically related to ES. However, the ES size varied from study to study, even for studies that were identical on all covariates; the test of zero-unexplained variance found there was heterogeneity; $\mathrm{Q}(29)=253.83, \mathrm{p}=.001, \mathrm{I} 2=88.58, \mathrm{R} 2=0.13$. These statistics mean the five-predictor model was not able to predict the effect size completely. It is very likely that there were other factors, apart from the five predictors, that influenced the variability of the effect size.

The four-predictor model was also statistically significant; $\mathrm{Q}(6)=14.79, \mathrm{p}=.02$. But, similar to the case of the five-predictor model, its goodness of fit was also lacking since the test of heterogeneity produced somewhat mediocre outcomes; $\mathrm{Q}(32)=274.78, \mathrm{p}=.001, \mathrm{I} 2=$ 88.35. The R2 of the four-predictor model was 0.22 . In sum, both models - the four-predictor and five-predictor models - demonstrated significant moderating effects of research design on mastery experience and teacher self-efficacy relationships, with limited explanatory efficacy.

Table 2 summarizes the results of testing whether each moderator is related to the mastery experience-teacher self-efficacy relationship for the five- and four-predictor models. Research design, one of the moderators that was defined as a set of two covariates, experimental and observational (survey) studies, each with the one-group pre-post studies serving as the reference group. The results yielded support for reliable associations between ES and research design in the two models; $\mathrm{Q}(2)=7.24, \mathrm{p}=.023$ (five-predictor model), and $\mathrm{Q}(2)=7.15, \mathrm{p}=$ .028 (four-predictor model). Experimental design was found to be an important and statistically significant predictor of the $\mathrm{ES} ; \beta=.32(95 \% \mathrm{CI}=.08, .56), \mathrm{z}=2.65, \mathrm{p}=.008$ (fivefactor model); $\beta=.31$ (95\% CI $=.18, .53), \mathrm{z}=2.67, \mathrm{p}=.008$ (four-factor model). In other words, research design moderated the relationship between mastery experience and teacher self-efficacy. This means to say that primary studies that used experimental manipulations 
yielded superior mastery experience-teacher efficacy relationships than did the studies that employed the survey method.

Table 2

Results of Meta-Regressions of 5-Predictor and 4-Predictor Models

\begin{tabular}{|c|c|c|c|c|c|c|c|c|c|c|c|c|c|}
\hline \multirow[b]{3}{*}{ Set } & \multirow[b]{3}{*}{ Covariate } & \multicolumn{5}{|c|}{ Model 1 (5 Predictors) } & \multicolumn{7}{|c|}{ Model 2 (4 Predictors) } \\
\hline & & \multirow[b]{2}{*}{ B } & \multirow[b]{2}{*}{ SE } & \multicolumn{3}{|c|}{$95 \% \mathrm{CI}$} & \multirow[b]{2}{*}{$P$} & \multirow[b]{2}{*}{ B } & \multirow[b]{2}{*}{ SE } & \multicolumn{3}{|c|}{$95 \% \mathrm{CI}$} & \multirow[b]{2}{*}{$p$} \\
\hline & & & & Lower & Upper & $z$ & & & & Lower & Upper & $z$ & \\
\hline Intercept & & -85.2 & 23.69 & -131.6 & -38.7 & -3.6 & .001 & -53.0 & 16.4 & -85.4 & -20.7 & -3.2 & .001 \\
\hline \multirow{2}{*}{ Design } & Experiment & .32 & 0.12 & .08 & .56 & 2.65 & .008 & .31 & .12 & .08 & .53 & 2.67 & .008 \\
\hline & Survey & .15 & 0.10 & -.04 & .34 & 1.56 & 119 & .10 & .08 & -.06 & .25 & 1.21 & .226 \\
\hline \multirow{2}{*}{ Sc Level } & Both P\&S & .26 & 0.10 & .07 & .45 & 2.69 & .007 & .19 & .09 & .02 & .36 & 2.23 & .026 \\
\hline & Secondary & .46 & 0.15 & .16 & .76 & 3.03 & .002 & .38 & .14 & .11 & .65 & 2.71 & .007 \\
\hline Culture & Western & .36 & 0.12 & .12 & .60 & 3.00 & .003 & .28 & .11 & .07 & .49 & 2.58 & .010 \\
\hline \multirow{2}{*}{ Publication } & Year & .04 & 0.01 & .02 & .07 & 3.6 & .001 & .03 & .01 & .01 & .04 & 3.22 & .001 \\
\hline & PTE & .30 & 0.16 & .00 & .61 & 1.94 & .053 & & & & & & \\
\hline \multirow[t]{2}{*}{ Measure } & PTSE & .10 & 0.13 & -.15 & .36 & 0.79 & 429 & & & & & & \\
\hline & SE & .15 & 0.10 & -.05 & .36 & 1.45 & .148 & & & & & & \\
\hline
\end{tabular}

The moderator school level also comprised a set of two covariates, which were studies that (i) included both the primary and secondary teachers, and (ii) examined secondary teachers only, while the group of studies on primary teachers was the reference group. The results yielded $\mathrm{Q}(2)=10.49, \mathrm{p}=.005$ (five-predictor model), and $\mathrm{Q}(2)=8.18, \mathrm{p}=.017$ (four-predictor model), evident of systematic relationships between ES and school level. In both models, studies on secondary teachers had contributed the most to the magnitude of ES.

Culture, in this meta-analysis, was defined as Western and Asian contexts that may predict the magnitude of ES between mastery experience and teacher self-efficacy. The metaregression showed that there was a difference in ES between studies of Western and Asian contexts; $\beta=.36(95 \% \mathrm{CI}=.12, .60), \mathrm{z}=3.00, \mathrm{p}=.002$ (five-factor model), and $\beta=.28(95 \%$ $\mathrm{CI}=.01, .49), \mathrm{z}=2.58, \mathrm{p}=.01$ (four-predictor model). Thus ES is related to culture. On the contrary, the mean effect size for the 39 studies provided no evidence of a difference between outcome measure and the ES. The results of the meta-regression has borne results which were not statistically different from zero, $\mathrm{Q}(3)=4.05, \mathrm{p}=.26$ (five-predictor model). In other words, the use of different teacher self-efficacy instruments did not have any impact on the ES. Hence, the predictor was excluded in the four-predictor model.

\section{DISCUSSION AND CONCLUSION}

The review revealed several noteworthy findings that may add to our understanding about teacher self-efficacy. First, the meta-analysis supported the expectation that mastery experience positively influences teacher self-efficacy. Fruitful in-service training enables teachers to make positive and meaningful reflections, judgments and expectations of being in control of their teaching tasks. Second, the hypothesized moderators, especially research design, school level, and culture, collectively explained the variability of the relationship between mastery experience and teacher self-efficacy. As expected, In addition, higher ESs were found among studies that involved secondary school teachers as well as those with both secondary and primary school teachers. It is possible that these two groups of sample might have shared richer and more diverse repertoire of experiences that strengthened their knowledge, skills, beliefs, confidence and conviction about making a difference in student learning. 
The meta-analysis found that cultural differences moderated the relationship between mastery experience and teacher self-efficacy. Studies conducted in the Western culture exhibited superior teacher self-efficacy. The finding is in keeping with many earlier observations that the Western culture empowers teachers to make instructional decisions and directions individually (Klassen \& Tze, 2014; Oettingen, 1995), in contrast to Asian teachers who follow highly structured, prescribed curricula. The empowerment enables Western teachers to become the creators of their own instructional performance. Consequently, teachers in this culture are more likely to reach higher levels of efficacy beliefs in comparison to their Asian counterparts.

The results of this brief meta-analysis offers practical contributions to educational practice and future research. First, it is imperative for policy makers to formulate requirements that could enact mastery experience among practicing teachers, particularly via a well-designed in-service training. The planning, implementation, and evaluation of an in-service training may include both primary and secondary school teachers. Second, there is a need for more experimental intervention and randomized controlled trials examining the effects of teacher efficacy in future studies. Well-planned experimental intervention studies will not only inform us about what makes a teacher efficacious. It will also enable research to profoundly advise and convince policy makers about evidence-based training programs to promote teacher selfefficacy that impacts on student learning positively. 


\section{REFERENCES}

*Azar, A. (2010). In-service and pre-service secondary science teachers' self-efficacy beliefs about science teaching. Educational Research and Reviews, 5, 175-188. Retrieved from http://academicjournals.org/journal/ERR/article-abstract/2543FF04015

Bandura, A. (1977). Self-efficacy:Toward a unifying theory of behavioral change. Psychologicl Review, 84, 191-215. doi.org/10.1016/0146-6402(78)900024

Bandura, A. (1997). Self-efficacy: The exercise of control. New York: Freeman

Borenstein, M., Hedges, L. V., Higgins, J. P. T., \& Rothstein, H. R. (2009). Introduction to meta-analysis. Chichester, UK: Wiley

*Bruce, C. D., \& Flynn, T. (2013). Assessing the effects of collaborative professional learning: Efficacy shifts in a three-year mathematics study. Alberta Journal of Educational Research, 58(4), 691-709. Retrieved from http://www.ajer.ca/

* Cadungog, M. C. (2015). The mediating effect of professional development on the relationship between instructional leadership and teacher self-efficacy. International Journal of Novel Research in Education and Learning, 2(4), 90-101. Retrieved from file:///C:/Users/U4171/Downloads/The\%20Mediating\%20Effect\%20of\%20Profession al-325\%20(4).pdf

*Cantrell, S. C., \& Hughes, H. K. (2008). Teacher efficacy and content literacy implementation : An exploration of the effects of extended professional development with coaching. Journal of Literacy Research, 40(1), 95-127. doi.org/10.1080/10862960802070442

* Chao, C. N. G., Forlin, C., \& Ho, F. C. (2016). Improving teaching self-efficacy for teachers in inclusive classrooms in Hong Kong. International Journal of Inclusive Education, 20(11), 1142-1154. doi:10.1080/13603116.2016.1155663

*Edwards, J. L., \& Newton, R. R. (1995, April). The effects of cognitive coaching on teacher efficacy and empowerment. Paper presented at the Annual Meeting of the American Educational Research Association (San Francisco, CA). [ERIC Reproduction Service No ED388654].

* Gaudreau, N., Royer, É., Frenette, É., Beaumont, C., \& Flanagan, T. (2013). Classroom behaviour management: The effects of in-Service training on elementary teachers' selfefficacy beliefs. McGill Journal of Education, 48(2), 359-382. doi:10.7202/1020976ar

* Ghanizadeh, A., \& Moafian, F. (2011). The Relationship between Iranian EFL teachers' sense of self-efficacy and their pedagogical success in language institutes. Asian EFL Journal, 13(2), 249-272. doi:10.1016/j.system.2009.09.014

Gibson, S., \& Dembo, M. (1984). Teacher efficacy: A construct validation. Journal of Educational Psychology, 76, 569-582. doi:10.1037/0022-0663.76.4.569 
* Haney, J. J., Wang, J., Keil, C., \& Zoffel, J. (2007). Enhancing teachers' beliefs and practices through problem-based learning focused on pertinent issues of environmental health science. Journal of Environmental Education, 38(4), 25-33. doi:10.3200/JOEE. 38.4.25-33

*Hensen, R. K. (2001). The effects of participation in teacher research on teacher efficacy. Teaching and Teacher Education, 17(7)), 819-836. doi:10.1016/S0742051X(01)00033-6

* Karimi, M. (2011). The effects of professional development initiatives on EFL teachers' degree of self efficacy. Australian Journal of Teacher Education, 36(6), 50-62. doi: 10.14221/ajte.2011v36n6.6

Klassen, R. M., \& Tze, V. M. C. (2014). Teachers' self-efficacy, personality, and teaching effectiveness: A meta-analysis. Educational Research Review, 12, 59-76. doi: 10.1016/j.edurev.2014.06.001

Kleinsasser, R. C. (2014). Teacher efficacy in teaching and teacher education. Teaching and Teacher Education, 44, 168-179. doi:10.1016/j.tate.2014.07.007

*Kosko, K.K.W., \& Jesse L. M. Wilkins, J. L. M. (2009). General educators' in-service training and their self-perceived ability to adapt instruction for students with IEP. The Professional Educators, 33(2). Retrieved from https://eric.ed.gov/?id=EJ988196

*Lee, S. E. (2013). Professional development and teacher perception of efficacy for inclusion (Doctoral dissertation, East Tennessee State University, USA). Retrieved from https://dc.etsu.edu/cgi/viewcontent.cgi?article=2295\&context=etd

Lipsey, M. W., \& Wilson, D. B. (2001). Practical meta-analysis. Thousand Oaks: Sage.

* Lumpe, A., Czerniak, C., Haney, J., \& Beltyukova, S. (2012). Beliefs about teaching Science: The relationship between elementary teachers' participation in professional development and student achievement. International Journal of Science Education, 34(2), 153-166. doi:10.1080/09500693.2010.551222

*Malinen, O. P., Savolainen, H., Engelbrecht, P., Xu, J., Nel, M., Nel, N., \& Tlale, D. (2013). Exploring teacher self-efficacy for inclusive practices in three diverse countries. Teaching and Teacher Education, 33, 34-44. doi:10.1016/j.tate.2013.02.004

* Mohamadi, F. S., Asadzadeh, H., Ahadi, H., \& Jomehri, F. (2011). Testing Bandura's theory in school. Procedia - Social and Behavioral Sciences, 12, 426-435. doi:10.1016/j.sbspro.2011.02.053

* Nordin, M.S. (2001). Sense of efficacy among secondary school teachers in Malaysia. Asia Pacific Journal of Education, 21(1), 66-74. doi:10.1080/02188791.2001.10594643

Oettigen, G. (1995). Cross-cultural perspectives on self-efficacy. In A. Bandura (Ed.), Selfefficacy in changing societies (pp. 149-176). New York: Cambridge University Press. 
Pajares, M. F. (1992). Teachers' beliefs and educational research: Cleaning up a messy construct. Review of Educational Research, 62(3), 307-332. doi:10.3102/00346543062003307

*Ransford, C. R., Greenberg, M. T., Domitrovich, C. E., Small, M., \& Jacobson, L. (2009). The role of teachers' psychological experiences and perceptions of curriculum supports on the implementation of a social and emotional learning curriculum. School Psychology Review, 38(4), 510-532.

Riggs, I. M., \& Enochs, L. G. (1990). Toward the development of an elementary teacher's science teaching efficacy belief instrument. Science Education, 74, 625-637. doi:10.12691/education-2-4-9

*Ross, J. A. (1994). The impact of an inservice to promote cooperative learning on the stability of teacher efficacy. Teaching and Teacher Education, 10(4), 381-394. doi:10.1016/0742-051X(94)90020-5

Sharma, U., Loreman, T., \& Forlin, C. (2012). Measuring teacher efficacy to implement inclusive practices. Journal of Research in Special Educational Needs, 12(1), 12-21. Doi:10.1111/j.1471-3802.2011.01200.x

* Swackhamer, L. E., Koellner, K., Basile, C., \& Kimbrough, D. (2009). Increasing the selfefficacy of inservice teachers through content knowledge. Teacher Education Quarterly, 36(2), 63-78. https://eric.ed.gov/?id=EJ857476

*Tschannen-Moran, M., \& Hoy, A. W. (2002, April). The influence of resources and support on teachers' efficacy beliefs. Annual Meeting of the American Educational Research Association. New Orleans, LA, 1-8. Retrieved from http://anitawoolfolkhoy. com/pdfs /aera-2002-megan.pdf

*Tschannen-Moran, M., \& Hoy, A. W. (2007). The differential antecedents of self-efficacy beliefs of novice and experienced teachers. Teaching and Teacher Education, 23(6), 944-956. doi:10.1016/j.tate.2006.05.003

* Tschannen-Moran, M., \& Johnson, D. (2011). Exploring literacy teachers' self-efficacy beliefs: Potential sources at play. Teaching and Teacher Education, 27(4), 751-761. doi:10.1016/j.tate.2010.12.005

*Van Acker, F., van Buuren, H., Kreijns, K., \& Vermeulen, M. (2013). Why teachers use digital learning materials: The role of self-efficacy, subjective norm and attitude. Education and Information Technologies, 18(3), 495-514. doi:10.1007/s10639-011-9181-9

* Woolfson, L. M., \& Brady, K. (2009). An investigation of factors impacting on mainstream teachers' beliefs about teaching students with learning difficulties. Educational Psychology, 29(2), 221-238. doi:10.1080/01443410802708895

*Yenice, N. (2009). Search of science teachers' teacher efficacy and self-efficacy levels relating to science teaching for some variables. Procedia - Social and Behavioral Sciences, 1(1), 1062-1067. doi:10.1016/j.sbspro.2009.01.191 
*Yeo, L. S., Ang, R. P., Chong, W. H., Huan, V. S., \& Quek, C. L. (2008). Teacher efficacy in the context of teaching low achieving students. Current Psychology, 27(3), 192-204. doi:10.1007/s12144-008-9034-X

*Zambo, D., \& Zambo, B. R. (2008). The Impact of Professional Development in Mathematics on Teachers ' Individual and Collective Efficacy: The Stigma of Underperforming. Teacher Education Quarterly, 35(1), 159-168. Retrieved from http:// www. teqjournal.org/

*Study included in the meta-analysis 